University of Nebraska - Lincoln

DigitalCommons@University of Nebraska - Lincoln

April 1999

\title{
Applications of amorphous track models in radiation biology
}

\author{
Francis Cucinotta \\ NASA Johnson Space Center, francis.cucinotta@unlv.edu \\ Hooshang Nikjoo \\ MRC, Radiation and Genome Stability Unit, Harwell, Didcot OX11 ORD, UK \\ Dudley A. Goodhead \\ MRC, Radiation and Genome Stability Unit, Harwell, Didcot OX11 ORD, UK
}

Follow this and additional works at: https://digitalcommons.unl.edu/physicskatz

Part of the Physics Commons

Cucinotta, Francis; Nikjoo, Hooshang; and Goodhead, Dudley A., "Applications of amorphous track models in radiation biology" (1999). Robert Katz Publications. 52.

https://digitalcommons.unl.edu/physicskatz/52

This Article is brought to you for free and open access by the Research Papers in Physics and Astronomy at DigitalCommons@University of Nebraska - Lincoln. It has been accepted for inclusion in Robert Katz Publications by an authorized administrator of DigitalCommons@University of Nebraska - Lincoln. 


\section{Applications of amorphous track models in radiation biology}

Received: 30 October 1998 / Accepted in revised form: 6 April 1999

\begin{abstract}
The average or amorphous track model uses the response of a system to gamma-rays and the radial distribution of dose about an ion's path to describe survival and other cellular endpoints from proton, heavy ion, and neutron irradiation. This model has been used for over 30 years to successfully fit many radiobiology data sets. We review several extensions of this approach that address objections to the original model, and consider applications of interest in radiobiology and space radiation risk assessment. In the light of present views of important cellular targets, the role of target size as manifested through the relative contributions from ion-kill (intra-track) and gamma-kill (inter-track) remains a critical question in understanding the success of the amorphous track model. Several variations of the amorphous model are discussed, including ones that consider the radial distribution of event-sizes rather than average electron dose, damage clusters rather than multiple targets, and a role for repair or damage processing.
\end{abstract}

\section{Introduction}

The average or amorphous track model was introduced by Katz over 30 years ago for describing the response of physical detectors or biological systems to heavy particle irradiation [1-3]. The key physical feature of this model is the use of the dose response for cell inactivation by gamma-rays as a mapping function that is correlated with the radial dose distribution from delta-rays produced about the path of the ion to predict the effects of ions [1-3]. In this paper, we review some of the strengths and weaknesses of this approach, and contrast

F.A. Cucinotta (-凶)

NASA Johnson Space Center, Mail Code SN,

Houston, TX 77058, USA

e-mail: Fcucinot@ems.jsc.nasa.gov

Tel.: 281-4830968; Fax: 281-4835276

H. Nikjoo · D.T. Goodhead

MRC, Radiation and Genome Stability Unit, Harwell,

Didcot OX11 0RD, UK the model to current views of radiation action. Several related models that use the radial dose profile to model radiobiology data are discussed along with applications of amorphous track models in radiobiology, therapy, and space radiation risk assessment.

In the mid-1960s, when Katz first introduced the radial dose model, contemporary knowledge of electron tracks was used for defining the properties of ion tracks in a 2-dimensional representation. In retrospect, this was a milestone departure from earlier models and brought to the forefront the importance of track-width and delta-ray effects in radiation action. The electron scattering data used at that time were electron production cross-sections from ion impact and range-energy, energy loss, and transmission functions. About 10 years ago, Goodhead [4] reviewed the amorphous track model and noted that the development of Monte Carlo track simulation codes in the 1970s and 1980s that provided 3-dimensional stochastic representations of electron and ion tracks [5, 6] could be used for new insights into the success of the Katz model. The importance of track simulation codes suggests that a modern phenomenological approach should use knowledge of electron tracks provided by Monte Carlo codes to describe heavy ion tracks. We discuss an example of this approach here.

Other than for pedagogical reasons, why are amorphous track models still useful in light of the development of the Monte Carlo track simulation codes? Mechanistic approaches to DNA damage and early chemistry have made much progress $[7,8]$ in describing the initial events produced by radiation, but for describing biological endpoints such as cell killing, chromosome aberration, or cancer induction, no truly mechanistic model exists, due to the enormous complexity of the biological processes involved. This is exemplified by advances in molecular biology over the last 10 years [9-12] that have begun to detail the molecular pathways that lead to cell killing. Many biophysics models have attempted to relate energy deposition and phenomenological treatments of damage repair to cell killing, but no mechanistic model currently exists that treats the many protein- 
mediated steps from initial damage through the induction of apoptosis [9, 10], or mitotic cell death $[11,12]$. The formation of chromosome aberrations is mediated by recombination processes [13, 14], and a role for signal transduction is known [15], so even here there are no complete mechanistic descriptions, although there are models that may make such claims. Amorphous track models have had many useful applications where extrapolations of radiation biology data are needed to other doses or dose-rates, other particle types, and for mixed field environments [1-3, 16-19]. Applications of the amorphous track models have been seen in radiobiology and cancer therapy with heavy ion beams, and in space radiation protection. We discuss some of these applications in this review.

\section{Energy deposition in the amorphous track model}

The use of radial dose profiles to model radiobiological effects recognizes some of the spatial features of the energy transfer events not described by linear energy transfer (LET). In order to discuss these, we first consider the relationship between LET and radial dose. The LET can be described by integrating the radial distribution over all radial distances up to the maximum allowable value, $t_{M}$, and including other contributions such as nuclear stopping,

$$
L E T=2 \pi \int_{0}^{t M} t d t\left[D_{\delta}(t)+D_{e x c}(t)\right]+\text { Nucl.Stopping }
$$

where contributions from ionization are denoted here as $D_{\delta}$, and excitations, $D_{e x c}$, are considered in the radial distribution. The value of $t_{M}$ is a function of ion velocity and corresponds to the range of electrons with maximum energy ejected by the passing ion, and thus defines the width of the track. The effects of nuclear stopping in radiation action have largely been ignored as is done here, and should only be important for very low energy ions $(<0.1 \mathrm{MeV} / \mathrm{u})$.

The model of Kobetich and Katz [20, 21] is one of the earliest for describing the delta-ray contribution, and most other models can be obtained as a reduction of it. This model was an extension of earlier work by Butts and Katz [1] that considered energy deposition by tracks in nuclear emulsion including the search for signatures of Dirac magnetic monopoles [22]. In this formalism, the primary electron spectrum from ion interactions with target atoms is folded with the average transmission properties of electrons to obtain the spatial distribution of electron dose as a function of radial distance from the ion's path. As introduced by Kobetich and Katz [20], the energy density distribution in a cylindrical shell of radius $t$, i.e. the radial dose, is written

$$
D_{\delta}(t)=-\frac{1}{2 \pi t} \sum_{i} \int d \Omega \int d \omega \frac{\partial}{\partial t}[E(t, \omega) \eta(t, \omega)] \frac{d n_{i}}{d \omega d \Omega}
$$

In Eq. (2), $\omega$ is the initial electron energy, $E$ is the residual energy of an electron with energy $\omega$ after traveling distance $t$, and $\eta(t, \omega)$ is the transmission probability that an electron with starting energy, $\omega$, penetrates a depth, $t$. Equation (2) includes an angular distribution for the number of primary electrons produced from target atom $i, n_{i}$, with energy, $\omega$, and solid angle, $\Omega$. In this model, electrons ejected directly by primary interactions and ones from secondary electron interactions are not resolved. The cross-sections for electron production from protons are scaled to heavy ions using the effective charge, $Z^{*}$, model of Barkas. Of note is that almost no data for production cross-sections are available for ions with energies above a few MeV/u [23]. Two modifications to Eq. (2) could be introduced in a straightforward manner. First, the electron transmission function could be modified to include an explicit angular dependence. Such functions have been described by Bethe et al. [24] and LaVerne and Mozumder [25] or could be obtained from Monte Carlo simulation codes [26, 27]. Second, the effective charge function could be replaced by one that includes a dependence on the ejection energy of the electron. The use of this type of an effective charge approximation may be especially important for ions with energies below about $1 \mathrm{MeV} / \mathrm{u}$. Equation (2) is easily solved by numerical integration where very general input functions can be used, as described by Cucinotta et al. [28]. Previous calculations have shown that the angular distribution has important effects on the radial distribution both for large and small radial distances, and only a minor effect at intermediate values where a $1 / t^{2}$ behavior holds. The $1 / t^{2}$ behavior of the radial dose profile has been used in several other models [29-34] and also found by Monte Carlo simulation codes (not reviewed here).

An analytic solution to Eq. (2) equivalent to the one introduced in the paper of Butts and Katz [1] is found by setting the transmission function to unity, assuming a normal ejection of electrons, and using the Rutherford cross-section with a linear relationship between electron energy and range. A linear relationship between energy and range implies that energy loss is independent of energy, which is certainly not true; however, the approximation works reasonably well over a modest range of ion energies. The models of Kiefer and Stratten [32] and Zhang et al. [33] are similar to that of Butts and Katz [1] where transmission effects are ignored, but more accurate electron range energy relations are used, and electrons are ejected at the classical ejection angle rather than normal to the path of the ion. We note that earlier work on studies of nuclear emulsions had considered some of these elements of radial dose profiles [29]. The models of Chatterjee et al. [30] and Fain et al [31] considered the individual contributions from glancing and knock-on collisions, and considerations of diffusive motion of low-energy electrons.

Brandt and Ritchie [35] have considered an ansatz for the radial dependence of the excitation term, $D_{e x c}(t)$, as

$D_{e x c}(t)=C_{e x c}(A, Z, \beta) \frac{\exp (-t / 2 d)}{t^{2}}$ 

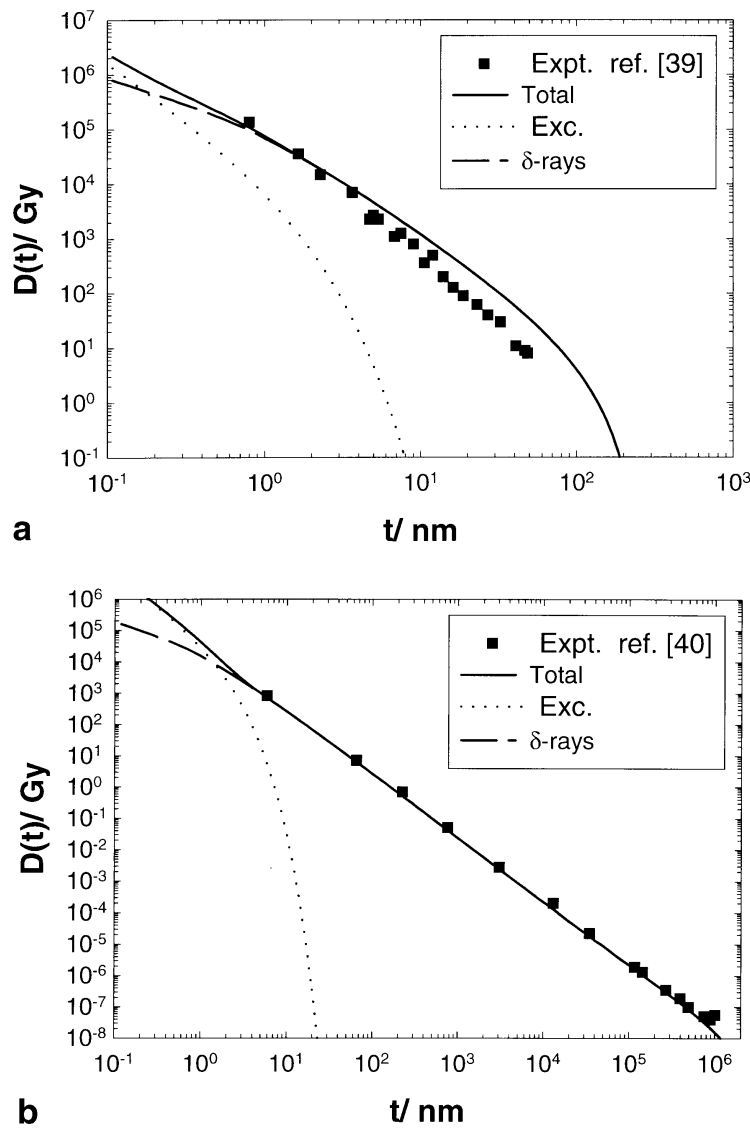

Fig. 1a-b Comparison of calculations of radial dose distributions to experiments $[39,40]$. Calculations show contributions from excitations and secondary electrons. a ${ }^{1} \mathrm{H}$ at $1 \mathrm{MeV}$ (linear energy transfer, LET $=27 \mathrm{keV} / \mu \mathrm{m}), \mathbf{b}{ }^{20} \mathrm{Ne}$ at $377 \mathrm{MeV} / \mathrm{u}(\mathrm{LET}=31 \mathrm{keV} /$ $\mu \mathrm{m})$

with $d=\beta / 2 h c /\left(2 \pi \omega_{\mathrm{r}}\right), c$ is the speed of light, $\beta$ is the ion velocity scaled by $c, h$ is Plank's constant, and $\omega_{r}=13 \mathrm{eV}$ for water. In Eq. (3), as described by Brandt and Ritchie [35], the radial extension of excitations is confined to very small distances, as characterized by the parameter $d$. The value of the parameter $C_{\text {exc }}$ can be adjusted such that after numerical integration of the terms on the righthand side of Eq. (3), the correct value of LET for an ion of mass number, $A$, charge number, $Z$, and energy, $E$, is reproduced. The LET representations for ions described in [36] are used in the calculations described below.

In the models of Chatterjee et al. [30] and Waligorski et al. [34], contributions from excitations are estimated. Waligorski et al. [34] used results from Monte Carlo simulations for high-energy proton as input. The model of Chatterjee et al. [30] employed a similar value for the radial extension of excitations as Brandt and Ritchie, but they assumed the distribution was constant within this region and have used an equipartition rule to separate contributions from glancing and knock-on collisions to the LET. The assumption of a constant distribution at small distances is removed in the more recent Monte Carlo simulations of Holley and Chatterjee [37]. It has been noted in the past $[27,38]$ that the equipartition model is not correct, since over $80 \%$ of the total energy loss arises from overcoming the electron binding and the kinetic energy of the liberated electrons. The contribution from excitations is expected to reflect only $5 \%-15 \%$ of the total energy loss [38], which is found in calculations using the Kobetich and Katz model [28]. Figure 1 shows comparisons between calculations and experiment $[39,40]$ for the average radial dose for $\mathrm{H}$ and $\mathrm{Ne}$ ions. It reveals the contributions from excitation and ionization. The ions shown are of nearly the same LET such that Fig. 1 illustrates some of the differences in track structure that occur due to track width effects. The radial dose profiles do not describe the stochastics of the events from individual electron tracks and the relative effectiveness for electrons of varying energies. These aspects of track structure are discussed below.

\section{Amorphous track models of radiation action}

Amorphous track models of radiation action are based on relating the gamma-ray dose response to the average properties of an ion track. Along with the ion kill-gamma kill (IGK) model of Katz, the models of Scholz and Kraft $[16,17]$ and Wilson et al. [18] have also used the radial dose and gamma-ray response to describe ion effects. We first discuss the approach of Katz and then the alternate features of other models. In the IGK model, the dose response from gamma-rays for a particular endpoint is utilized as a mapping function by assuming that the response at a particular value of radial dose is equivalent to gamma-rays at that dose level. The summation of contributions from all radial distances yields the action cross-section of the ion. The action cross-section which defines the contribution from single particles is evaluated as [1]

$\sigma_{1}=2 \pi \int_{0}^{t M} t d t P_{1}\left(D_{\text {ave }}(t)\right)$

where $D_{\text {ave }}(t)$ is the radial distribution of energy deposition averaged over the cross-sectional area of a cylindrical target with radius $a_{0}$, assumed to lie perpendicular to the path of the ion, and $P_{I}$ is the gamma-ray dose response of the system for inactivation. Two cases have been considered by Katz, corresponding to exponential and shouldered survival curves. For a system with an exponential response to high-energy photons with characteristic dose, $D_{0}$, the fraction of survivors is determined by the particle fluence, $F$, and $\sigma_{I}$

$\frac{N}{N_{0}}=\exp \left(-\sigma_{I} F\right)$

For these so-called one-hit systems, there is no intertrack component. This approach has been shown to provide accurate fits to data in many non-mammalian systems such as the inactivation of enzymes and viruses [1, 3]. DNA damage has been considered, for example, in simian virus (SV40) held in E0 buffer where the sensitivity of DNA is increased and a larger role for indirect 


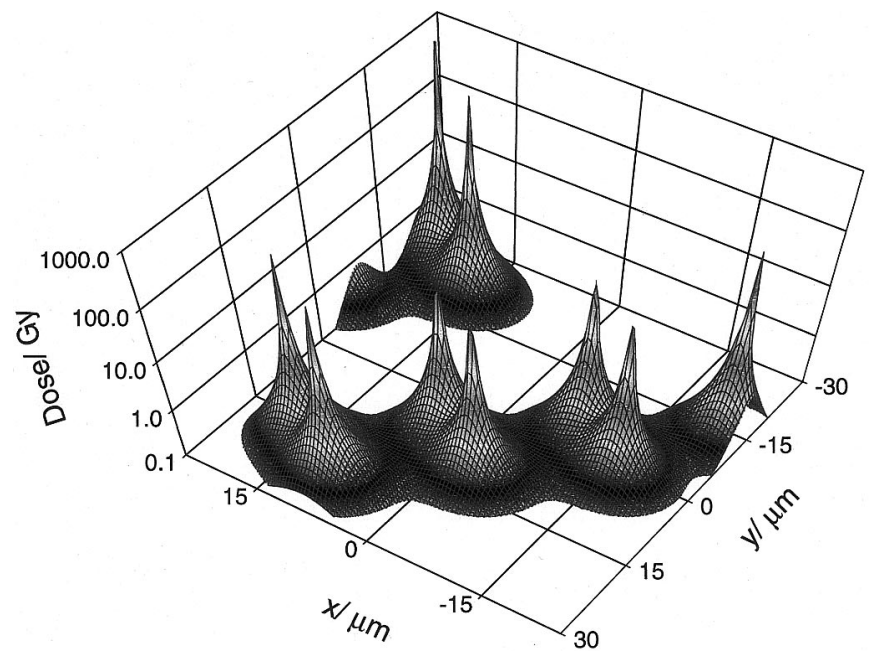

Fig. 2 Calculations of random tracks of $20 \mathrm{MeV} / \mathrm{u}{ }^{56} \mathrm{Fe}$ passing through a plane of cells of $15 \mu \mathrm{m}$ diameter. The combined radial dose contributions from several tracks are plotted in order to illustrate the spatial distribution where ion-kill and gamma-kill predominate in the amorphous track model. A lower threshold of $10 \mathrm{cGy}$ is assumed

effects is expected [41]. In almost all cases, for one-hit systems the target radius parameter, $a_{0}$, is on the order of $100 \mathrm{~nm}$ or less, and often a point-target approximation can be used accurately, leaving only a single parameter, $D_{0}$, to be determined directly from gamma-ray response curves. For treating DNA damage, Kraft and Krämer [38] have noted that the model of Katz treats single- and double-strand breaks (SSB and DSB) induction as separate processes, which is unrealistic. A more recent calculation using the amorphous track model [42] of DNA damage in mammalian cells extended the model to consider the formation of DSB from individual SSB. The agreement with experimental data was satisfactory, but comparisons to Monte Carlo simulations of DNA damage [6] indicated important differences [42], especially for $\mathrm{H}$ and $\mathrm{He}$ ions below $1 \mathrm{MeV} / \mathrm{u}$.

The second case considered by Katz and co-workers is survival in mammalian systems with shouldered survival curves [2]. Here intra-track and inter-track processes are assumed, with the intra-track term described by Eqs. (4) and (5) using a multi-target model for $P_{I}(D)$ with parameters $D_{0}$ and $m$ and one other modification. The multi-target model assumes that there is an accumulation of sublethal damage due to delta-rays from more than one ion track. In the model for inactivation of mammalian cells, the action cross-section is re-scaled by the factor $\sigma_{0} / 1.4 \pi a_{0}^{2}$, which represents the ratio of the area of an assumed sensitive part of the cell nucleus to that of an individual target, which Katz describes using a beans in a bean-bag analogy. The inter-track contribution is found by considering the fraction of the dose or fluence not contributing to ion-kill, which defines a new quantity denoted the gamma-kill dose, $D_{r}$ as

$D_{\gamma}=\left(1-\frac{\sigma_{I}}{\sigma_{0}}\right) D$
The dose response for survival is then found as

$$
\frac{N}{N_{0}}=\exp \left(-\sigma_{I} F\right)(1-P(D \gamma))
$$

Figure 2 depicts a plane of cells intersected by several random tracks of $20 \mathrm{MeV} / \mathrm{amu}{ }^{56} \mathrm{Fe}$ particles (represented by their radial dose profiles) and serves to illustrate the IGK model. Here the large density region close to the path of an ion is where the ion-kill model predominates. At distances away from the centre of a track, the combined contribution from delta-rays of several tracks becomes more influential. Also, there are several cells that are not hit at all by delta-rays above a given dose level (shown here as $0.1 \mathrm{~Gy}$ ). In applying Eq. (4), the details of the values of the radial dose become diminished close to the track, especially for high $Z$ ions, since the integrand in Eq. (4) approaches unity for small $t$. Here the added contributions from excitations have a small effect except for low-LET ions [35].

For multi-target systems the cross-section of Eq. (4) is accurately approximated by the following function when the value of the parameter, $Z * 2 / \beta^{2}$, is below a cut-off value

$\sigma_{I}=\sigma_{0}\left(1-\exp \left(-\frac{Z^{* 2}}{\kappa \beta^{2}}\right)\right)^{m}$

where $\sigma_{0}$ is the saturation value of the cross-section where an inflection occurs. The region where $\sigma_{I}<\sigma_{0}$ is denoted the grain count region and $\sigma_{I}>\sigma_{0}$ denoted the track-width regime $[2,3]$. As the velocity of an ion is lowered, the cross-section falls rapidly, which is denoted as the thin-down region. The value of the dimensionless parameter $\kappa$ is given by

$\kappa=D_{0} a_{0}^{2} /\left(2 \times 10^{-11} \mathrm{~Gy} \mathrm{~cm}^{2}\right)$

The IGK model has had much success in predicting the effects of a large number of radiation types including the change in radiation quality and the transition from shouldered to exponential survival curves as the LET of the radiation field is increased. Several aspects of the change in the shape of the action cross-section with particle type and model parameters are described by the following example. In Fig. 3a, calculations with the IGK model are compared to data [43-46] for V79 inactivation. The parameters used for inactivation of V79 cells are shown where $m=3, D_{0}=1.8 \mathrm{~Gy}, \sigma_{0}=43 \mu \mathrm{m}^{2}$, and $a_{0}=1.1 \mu \mathrm{m}$. The model provides a very good quantitative representation of the experimental data with a small number of parameters. One of the few successful theoretical predictions made in radiobiology was the predictions of hooks in the plot of action cross-sections due to thin-down when the width of the track narrows below the size of the sensitive region of the cell $[1,2]$.

Several considerations of the values of target size used in the IGK model for inactivation are of interest. The model cross-sections for protons and helium ions as evaluated from Eq. (4) will display hooks that are not observed experimentally. For example, with protons the hook occurs at about $2 \mathrm{MeV}$, corresponding to a LET of 

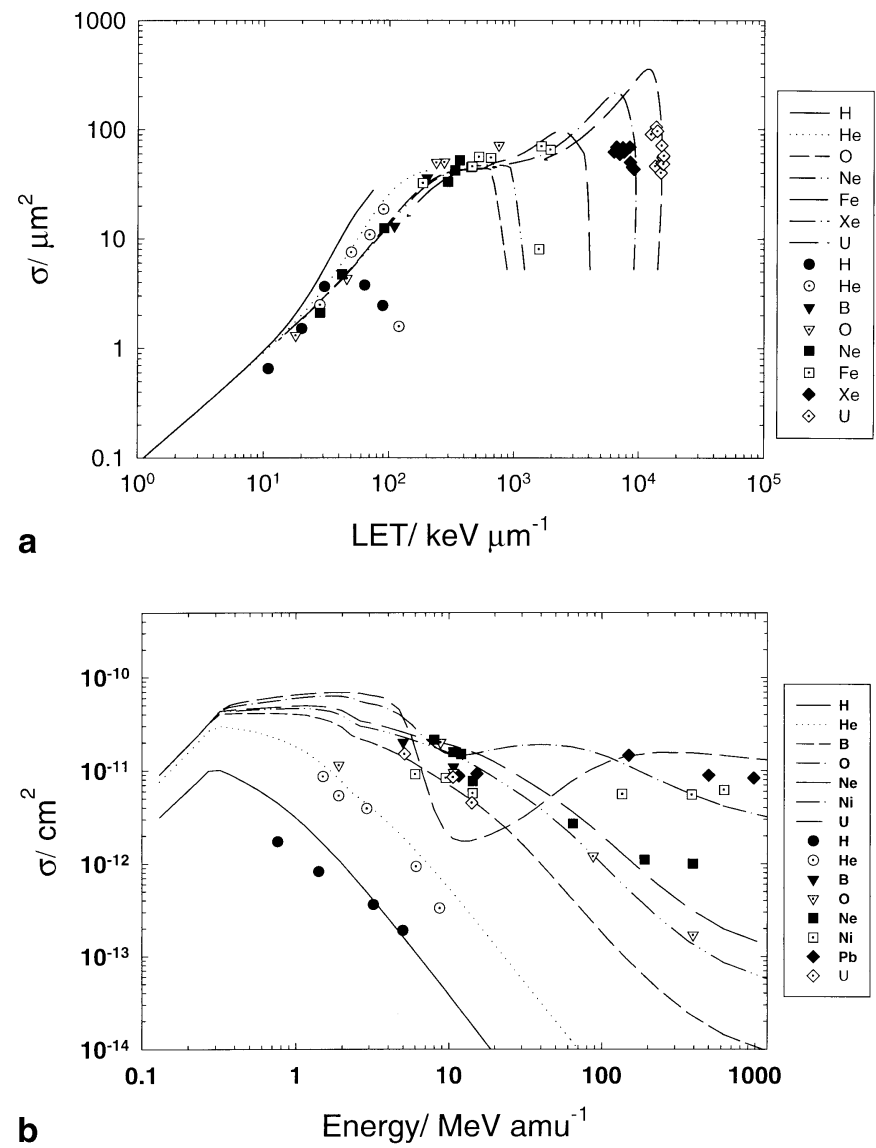

Fig. 3a-b Comparison of calculations of action cross-sections for inactivation of V79 cells versus LET for several ion types to experimental values [43-46]. b Comparison of calculations of action cross-sections for HPRT mutation in V79 cells versus energy for several ion types to experimental values [43-46]

$10-15 \mathrm{keV} / \mu \mathrm{m}$. If the grain count cross-section of Eq. (8) is used for low energy and charge ions, these low $Z$ hooks do not occur, and an accurate fit to experimental data is often found. Also, if a smaller target size is used, the position of the hook shifts to lower energy values and for protons becomes consistent with expectations from neutron radiobiology data where the peak value in biological effectiveness is for energies around $0.5 \mathrm{MeV}$. For ions with a large charge, the energy corresponding to the position of the hook is less sensitive to target size. The cross-section in the track-width regime for higher charged ions rises above the saturation value and also the nuclear area for the V79 cells of $130 \mu \mathrm{m}^{2}$. Such large cross-sections have not been observed experimentally for V79 cells, but there are several more sensitive cell lines where values exceeding the geometrical limit have been observed. Examples include human lymphocytes [47] and the repair-deficient LS1784 S/S cells [48]. For small impact parameters the model of Eq. (4) predicts unit probability for cell killing. Experiments made at fixed impact parameters with high $Z$ ions for bacterial spore inactivation [49] did not find such large values. However, in [50] calculations (as shown in Fig. 4) with the IGK
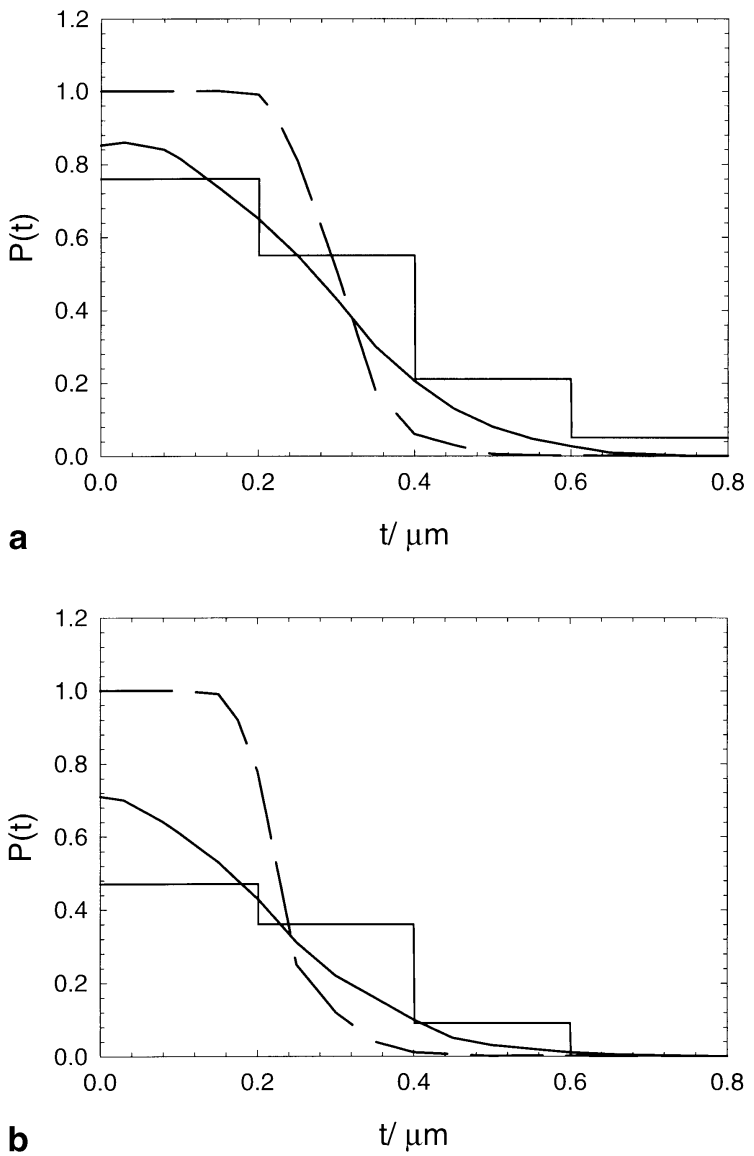

Fig. 4a-b Comparison of calculations of the inactivation probability versus radial distances for bacterial spores to experiment [49] for 1.4 MeV/amu U. b Comparison of calculations of the inactivation probability versus radial distances for bacterial spores to experiment [49] for $1.4 \mathrm{MeV} / \mathrm{amu} \mathrm{Ni}$. All calculations were performed assuming an impact parameter relative to the centre of the spore (dashed line) or to the DNA content assumed to be randomly positioned in the spore volume (solid line)

model showed that when the impact parameter (assumed to be relative to the centre of the spore) was corrected by assuming the DNA was positioned with equal probability anywhere in the spore volume, good agreement of the model and experimental data was found, and large inactivation probabilities for ions that pass directly through the spore was not ruled out.

The IGK model has considered mutations in mammalian cells [51], including the effects of inactivation on single-track action. The recognition of the effects of inactivation on mutation yields has been discussed in biophysical models for many years [52]. The IGK calculations described such effects by modelling the track-structure effect resulting from the spatial distribution of targets for inactivation and mutation [51]. For predicting mutation effects, the dose response for gamma rays, $P_{M}$, is considered along with the probability of expression of the mutation as determined by $P_{I}$. The targets for mutation and inactivation are treated as distinct. The target for mutation is assumed to be the DNA of the gene of interest, and the target for inactivation non-specific through- 
out the genome. The model assumes that a random distance, $r$, from the target gene separates the sites for inactivation. The volume of the cell nucleus restricts the maximum value of $r$. The cross-section for mutation corrected for single-particle inactivation effects is given by

$\sigma_{M}=2 \pi \int_{0}^{t M} t d t P_{M}\left(D_{\text {ave }}(t)\right) \frac{1}{V_{N}} \int d \mathbf{r}\left(1-P_{I}\left(D_{\text {ave }}(\mathbf{t}-\mathbf{r})\right)\right.$

where $V_{N}$ is the nuclear volume. The gamma-ray doseresponse function for inactivation and mutation probability functions are fitted to data using convenient forms for these functions such as the multi-target or multi-hit models.

Comparisons of calculation [51] to experiments [43-46] for HPRT mutation in V79 cells are shown in Fig. 3b. The data are from Belli et al. [43] for protons and helium ions, Thacker et al. [44] for B ions, and Kiefer and co-workers $[45,46]$ for other heavy ions. A prediction of the model is that a depletion of the mutation cross-section occurs at energies where the inactivation cross-section is a maximum. The calculations show that inactivation has a large effect on the expression of mutants for heavy ions. Experiments comparing the expression of mutation at the HPRT and TK loci in human lymphoid cells that are wild-type or mutant for $\mathrm{p} 53$ protein show increased levels of mutation in the mutant p53 cell lines [53]. Mutant p53 cell lines will have diminished apoptosis capacity after radiation exposure such that the survival response becomes more resistant. Both interphase cell death (correlated with p53 expression and apoptosis in many cell lineages) and mitotic cell death contribute to cell inactivation by ions $[47,54]$. The IGK model does not consider such fundamental aspects of biology, but they are represented in the model by the inherent sensitivity of cells to photons. The considerations of the IGK model on track-structure effects and inactivation would provide an interesting analysis of HPRT mutation data in mutant p53 cells.

Kozubek et al. [55] have modelled mutation induction in bacteria employing the radial dose profile. In this model, the radial dose is used to evaluate the fraction of energy deposition where the ion does not pass through a sensitive structure with such occurrences denoted as indirect events. The mutation efficiency is assumed to be directly proportional to this fraction multiplied by the total LET. This model differs from the approach of other amorphous track models $[1-3,16-18]$ since the response of the bacteria to gamma-rays is not considered.

The model of Katz is a phenomenological description of radiation action that has been quoted as being the most successful approach for fitting heavy ion data. Keeping in mind its phenomenological basis, some of the objections to the Katz model are that it does not describe damage repair, the lack of any initial slope for gamma-rays when treating shouldered survival curves, the use of target sizes for inactivation of mammalian cells that are orders of magnitude larger than DNA targets believed to control damage processes, and ignorance of the properties of the stochastics of particle tracks and the relative effectiveness of electrons of varying energy. Goodhead [4] has stated that the values of the parameters of the IGK model for inactivation of mammalian cells have no useful literal interpretation, but for endpoints such as mutation, these parameters are similar to expectations derived from knowledge of important DNA structures, etc. For mutation, the IGK parameters are more reasonable with respect to the size of genes and the average energy deposited in the gene for the mutation to occur [4]. We note that the addition of a linear component to the gamma-ray response does not substantially alter the results of the IGK model if the linear component is not large (for e.g. $\alpha_{\gamma}<0.1 \mathrm{~Gy}^{-1}$ for V79 cells). Another concern is for applications to the inactivation of mammalian cells where the gamma-ray response is exponential, and values of relative biological effectiveness (RBE) are greater than unity. Here the IGK model requires a singletarget model (one-hit), and the RBE will be less than unity. Some of these objections are addressed by related models as described below.

The model of Wilson et al. [18] uses a multi-hit linear kinetics formalism to describe radiation action. This model is closely related to a state-vector or population kinetics approach where nascent populations in various states of damage are considered and linear transitions occur between presumed damaged and repaired/misrepaired states. As the number of hits accumulates, the possibility of repair is assumed to diminish, and misrepair or damage fixation dominate. Competition between lesions for mutation or inactivation are considered as well as cell-cycle effects [18]. In this model, the trackstructure picture of Katz is adapted by allowing transitions to fixed states to occur, as described by the ion-kill cross-section, while transitions between non-fixed states by radiation are described by the gamma-kill dose. This model has also been applied within the two-stage tumour induction model of initiation-promotion and compared to the high charge and energy (HZE) ion-induced tumour studies in the Harderian gland of the mouse [56, 57]. By utilizing the amorphous track model of Katz, many objections, but not all, are avoided in a kinetics framework including a phenomenological description of damage repair and an initial slope for the gamma-ray response [18]. This type of approach has many useful applications for extrapolating radiobiology data to environmental conditions.

The model of Scholz and Kraft [16], denoted as the local effects model (LEM), has been introduced as an alternative to the IGK model for cell inactivation, especially for mammalian cells. In the LEM model, the radial dose distribution and photon response are used to describe the radiation action of ions, but there are important differences between this model and the IGK model. The LEM model considers extended targets by using the local effects inside small compartments throughout the nucleus. The probability of inducing a lesion from each compartment is integrated over the nuclear volume (assumed to lie parallel to the ion's track). Monte Carlo techniques are employed to sum the contributions from 
various ion tracks, thus losing the simplicity of the IGK model where the contributions from inter-track effects are summed conveniently through the gamma-kill dose. The size parameters in the model are not fitted to experimental data as done in the IGK model; instead the crosssectional area of the cell nucleus is assumed to be the target for inactivation.

Several differences between the two models are less consequential: these include which radial dose model is employed and which mathematical form for the photon survival curve is used. Scholz and Kraft [16] have discussed that two separate modes of inactivation are not invoked in the LEM model, as is done in the IGK model. However, in the IGK model the gamma-kill and ion-kill modes both originate from the photon dose-response curve: ion-kill through the formation of the action crosssection, and gamma-kill directly in terms of the gammakill dose, which introduces the parameter $\sigma_{0}$. In order to avoid the necessity of Monte Carlo sampling to include contributions from multiple tracks, Scholz et al. [17] have introduced an approximation scheme where an $\alpha-\beta$ model for the ion dose response is used with the value of $\alpha$ from the one-track contribution and the $\beta$ term an approximation to multiple-track contributions. This type of approximation is very useful for applications and, although done in a distinct manner, very much follows the spirit of ion-kill and gamma-kill modes introduced by Katz, and unavoidably introduces a new parameter to predict inter-track contributions.

The major difference between the two models is the treatment of targets in the LEM model, which leads to one less parameter than in the IGK model (if identical photon-response curves). We expect, based on their common use of the radial dose profiles, that the Katz model and the approach of Scholz and Kraft should give similar results for small targets $(<100 \mathrm{~nm})$, but some differences will arise when describing the inactivation of mammalian cells. These differences would be most notable for ions with energies such that the width of their tracks are similar to or smaller than the diameter of the cell nucleus $(\mathrm{E}<5 \mathrm{MeV} / \mathrm{u})$. Direct numerical comparisons between the two models are needed for understanding the importance of these differences in fitting radiobiological data sets. Such comparisons would be most useful if identical radial dose models and functional forms to fit $\mathrm{x}$-ray or gamma-ray dose response were used.

\section{Tissue damage from HZE ions}

The amorphous track models have been used extensively to consider applications in cancer therapy using heavy ion irradiation $[2,16,17,58,59]$. When combined with models of radiation transport $[60,61]$, these models can provide important insights into the nature of therapy from different particle beams. Model descriptions of the spread-out Bragg peak (SOBP) are useful to estimate the effectiveness of ions for cell killing, including the role of sparing by such beams. In the SOBP there will be a low-
LET component due to the fragmentation of the beam or tissue fragments, especially knock-out protons, which will be dependent on the size of the peak. In the IGK model, the fraction of the dose delivered in the gammakill mode enjoys the same advantages for therapy as gamma-rays, such as repair, re-population and re-oxygenation. On the other hand, the fraction of the dose delivered in the ion-kill model will not display these characteristics since by definition no repair occurs. Katz has described the use of high $\mathrm{Z}$ beams for therapy as analogous to radiation surgery, and clearly proton beams are preferable if repair, re-population, etc. are advantageous in treatment planning. There are other tissue effects that become possible with high charge and energy (HZE) ions at low dose or dose rate due to their large range and high efficiency for cell inactivation.

The possibility of heavy ions causing unique tissue damage at low doses was noted by Grahn [62] and Todd et al. [63, 64]. Todd introduced the micro-lesion concept [64] to consider the role of stochastics in tissue events that occur with HZE tracks and the possibility of unique types of tissue damage. Micro-lesion formation is of especial concern regarding damage to the brain or central nervous system (CNS) where fully differentiated structures are present that cannot be replaced if damaged. Todd has also discussed the importance of tissue structure including the role of track traversal of multiple stem cells in some tissues, but not others, and the resulting effects on RBE. These considerations indicate that some tissues would be more sensitive to the stochastics of tissue events than others. Radiation-induced cell death in neurons is now known to occur through p53-induced apoptosis [65]. This is interesting in the light of earlier results of Lett and Williams [66] where late degradation of DNA in the photoreceptor cells of rabbits exposed to $\mathrm{Fe}$ irradiation was observed but not with low-LET irradiation. It is difficult to judge whether evidence exists for the importance of unique effects in tissue from HZE due to the lack of experimental studies. We next consider several examples using the amorphous track model that suggest that such possibilities do exist.

The amorphous track model for cell killing can be used to describe the stochastics of tissue events. In Fig. 5, we show a Monte Carlo simulation of the linear array of inactivated cells produced by $\mathrm{He}, \mathrm{Ne}$ and $\mathrm{Fe}$ tracks of $1 \mathrm{~cm}$ range. The method for the simulations follows the approach of Katz and Hoffman [67], with cell killing parameters of $m=3, D_{0}=2.8 \mathrm{~Gy}$, and $\sigma_{0}=50 \mu \mathrm{m}^{2}$ and a cell layer density of 1 cell per $25 \mu \mathrm{m}$ used in this example. Iron particles are observed to have a density for cell kill of greater than $80 \%$ for more than 200 cell layers, indicating a possible concern for sensitive areas of the brain where essential neurons are located. In Fig. 6 we show a tissue event that can occur after nuclear fragmentation induced by high-energy nuclear particles including protons $[38,68,69]$. Here we have selected a ${ }^{16} \mathrm{O}$ to $4 \alpha$ event assuming isotropic fragment production in the tissue rest frame and sampling from the energy distribution for alpha-production [69]. This example is representative 


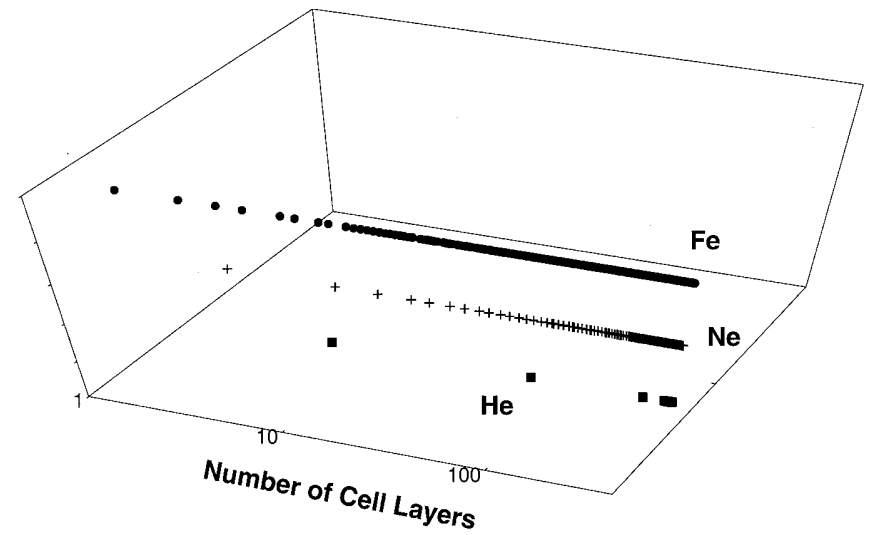

Fig. 5 Simulations of the linear array of inactivated cells from tracks of ${ }^{4} \mathrm{He},{ }^{20} \mathrm{Ne}$, and ${ }^{56} \mathrm{Fe}$ of initial range of $1 \mathrm{~cm}$ in tissue. Tracks enter from left and stop on the right in the figure. Cells are assumed to be spaced 1 per $25 \mu \mathrm{m}$

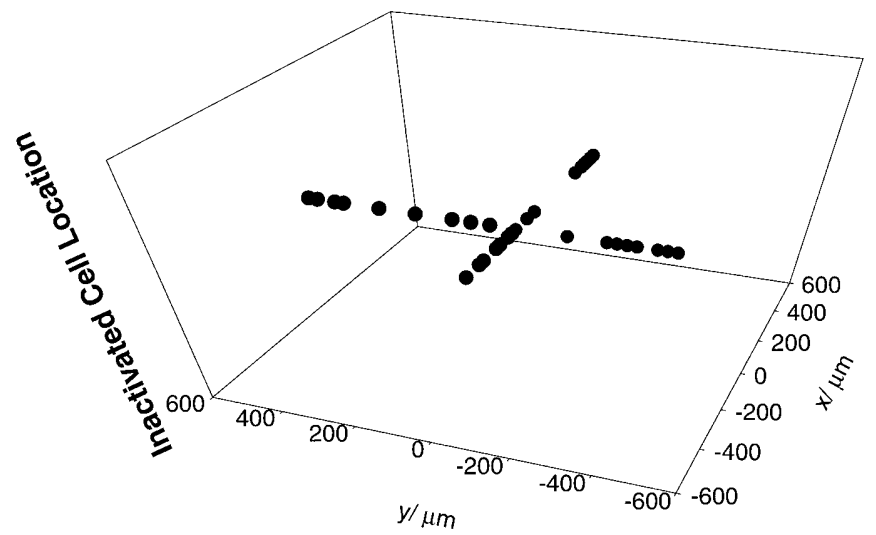

Fig. 6 Simulations of the positions of inactivated cells after a nuclear fragmentation event produced by a high-energy particle where ${ }^{16} \mathrm{O}$ is fragmented to 4 alpha-particles. The alpha-particles are assumed to be produced isotropically in the tissue rest frame, and their starting energy is found by random sampling from their production cross-section

of an important fraction of the proton- $16 \mathrm{O}$ absorption cross-section, being typical of the many multi-particle production channels that occur in fragmentation at high energy $[38,68]$. The calculation in Fig. 6 illustrates that low-energy target fragments will deposit all of their energy within a few cell layers from the nuclear interaction site. Therefore, in the tissue traversal of a single lowLET proton, an event where 1 Gy or more of energy is deposited within a few cell layers can occur with high frequency. Current estimates of the RBE for high-energy protons may not be indicative of such processes since they are largely based on cell culture models at high doses. Here the contribution of nuclear events may be overshadowed by the large primary dose, and the 3-dimensional structure of the event would not be fully apparent in vitro. The severity and frequency of these events increase with particle energy since the nuclear absorption cross-section is minimum near the pion production threshold $(290 \mathrm{MeV})$ and then rise to energies of about
$1000 \mathrm{MeV}$. It is doubtful that stochastic tissue effects from the high energy ( $>200 \mathrm{MeV}$ ), low-LET component of space radiation can be understood from existing radiobiology data for protons with energies of $200 \mathrm{MeV}$ or less using cell culture models.

Genomic instability refers to the appearance of delayed chromosome abnormalities, mutation or lethality in the progeny of irradiated cells seen with both highand low-LET radiation [70, 71]. A recent study using low-energy alpha-particle beams indicates that genomic instability in vitro, as measured by the appearance of delayed chromosome aberrations, is as prevalent in neighbouring cells as in cells that received direct traversals of alpha-particles [72]. If such effects are found to be important in vivo as well, clearly they would have a large importance for HZE ions which traverse many layers of cells in tissue because of their large ranges. The calculations discussed above did not consider lateral damage to neighbouring cells in particle traversals. The number of cells hit in the passage of single particles increases by a large factor for HZE, as shown in a recent paper [73] which considered the average track to estimate the lateral brush of delta-rays above a radial dose threshold of 1 $\mathrm{mGy}$ or $1 \mathrm{cGy}$. These calculations showed that the use of LET and cell area to estimate the number of cells affected largely underestimates the true number. In considering bystander effects such as the release of apoptotic products or cell signalling events, additional lateral damage may prove to be important due to the large number of cells incurring such damage in the passage of single HZE tracks in tissue.

\section{Energy deposition in DNA and radiation action}

Goodhead has discussed the similarities of cross-sections derived from Monte Carlo track simulation codes for protons and alpha-particles with the model of Katz [4]. Recently, we have used (Cucinotta et al. 1999, manuscript submitted) the results of Monte Carlo simulations for electron tracks and the radial electron spectrum derived from the Kobetich and Katz model [74] to consider radial frequency-distribution profiles from heavy ions. We next describe these distributions and their application to inactivation probabilities from heavy ions following the approach introduced by Goodhead [4].

Monte Carlo track simulations score energy deposition events from individual electron tracks in a homogeneous medium such as water. One output of the simulations is absolute frequency distributions for energy deposition in various target sizes. To consider frequency distributions from particles, we have described contributions from primary-ion interactions, $f_{\text {ion }}$, and from deltaray events, $f_{\delta}$. These contributions are added by using the number of events as a function of the impact parameter, $n_{e v}(t)$, to weight the normalized frequency spectrum such that the total distribution is (Cucinotta et al., 1999, manuscript submitted) 
$\frac{d F(\varepsilon)}{d \varepsilon}=2 \pi \int_{0}^{t M} t d t \quad n_{e v}(t) \quad\left[f_{i o n}(\varepsilon, t)+f_{\delta}(\varepsilon, t)\right]$

The number of events at radial distance, $t$, can be expressed as,

$n_{e v}(t)=\frac{D(t)}{\bar{z}_{F}(t)}$

where $\bar{z}_{F}(t)$ is the frequency-averaged mean specific energy at $t$. The contributions from primary-ion events are modelled by evaluating the mean and variance of the energy transfer distribution corrected for the range of diffusion of electrons, and assuming a log-normal distribution (Cucinotta et al., 1999, manuscript submitted). The frequency distribution from delta-rays is evaluated by assuming the radial distribution of electrons, $\phi(E, t)$, of energy, $E$, is incident on a volume at distance, $t$, from the track centre and folding this spectrum with the frequency distribution evaluated by Monte Carlo simulation for electrons of a given energy

$f_{\delta}^{(1)}(\varepsilon, t)=\int d E \quad \phi(t, E) f_{e^{-}}(E, \varepsilon)$

where the distributions $f_{e^{-}}(E, \varepsilon)$ are the events of size, $\varepsilon$, produced by electrons in a particular volume. The frequency distribution for electrons are from the published results of Nikjoo et al. [75]. For higher charged ions, overlapping electron tracks may occur at impact parameters close to the target volume. Higher order delta-ray terms are included using the Poisson distribution and the radial distribution of the number of events where the $f_{\delta}^{(1)}$ are the convolutions of the single-event distribution [74]

$f_{\delta}(\varepsilon, t)=\sum_{j=1} \frac{e^{-n(t)}}{j !} n(t)^{j} f_{\delta}^{(j)}(\varepsilon, t)$

The radial electron spectrum can be combined with the relative effectiveness of electrons of varying energy to consider the relative effectiveness as a function of radial distance from an ion's path. Figure 7a shows the RBE vs electron energy estimated from experiments [7] for the inactivation of V79 cells by X-rays at several energies or from Monte Carlo track structure simulations for the frequency of energy deposition above $120 \mathrm{eV}$ in DNA by electron tracks [76]. In Fig. 7 b we show calculations for several ion energies of the radial distribution or RBE using the electron RBE shown in Fig. 7a. The increased contributions from the softer electron distribution close to the track and at the maximum range of the delta-rays is clearly seen in these calculations. The results shown are nearly independent of ion charge because of the effective charge approximation used in the calculations.

Figure 8 shows comparisons of the model for 200 $\mathrm{MeV} / \mathrm{u}{ }^{12} \mathrm{C}$ ions, 200 and $600 \mathrm{MeV} / \mathrm{u} 56 \mathrm{Fe}$, and 1 and $5 \mathrm{MeV} / \mathrm{u}{ }^{4} \mathrm{He}$ ions. The comparisons in Fig. 8 reveal that relativistic ${ }^{56} \mathrm{Fe}$ ions produce many low-energy deposition events from energetic delta-rays along with high-energy events. Models of DNA damage use energy deposition thresholds of 10-25 eV for SSB induction, and
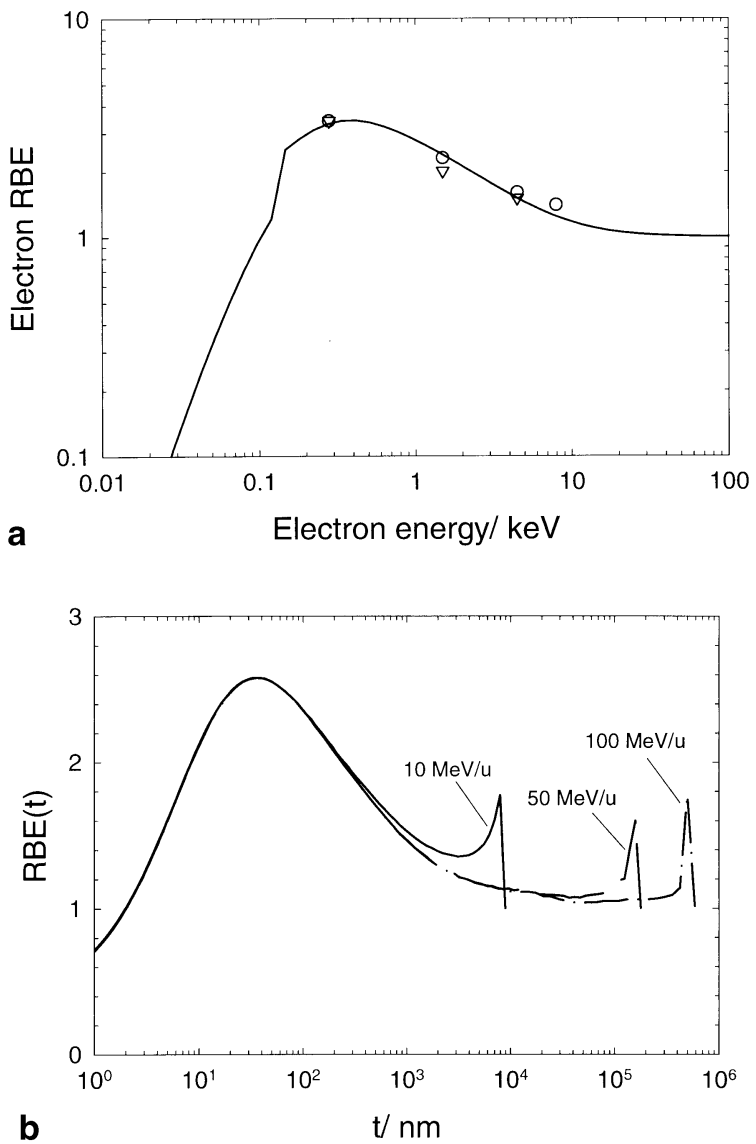

Fig. 7a-b Relative biological effectiveness (RBE) vs electron energy estimated from experiments (triangles) for inactivation of V79 cells by x-rays at several energies or from Monte Carlo track structure simulations (circles) for the frequency of energy deposition above $120 \mathrm{eV}$ in DNA by electron tracks described by Goodhead and Nikjoo [7]. b The relative effectiveness along an ion track as a function of radial distance due to the change in electron spectra for several primary ion energies. The electron RBE shown in $\mathbf{a}$ are used in the calculations

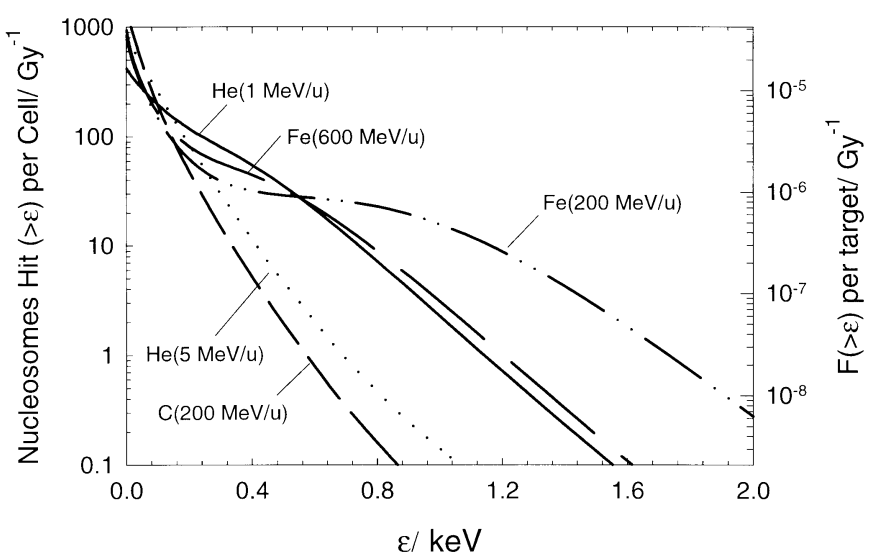

Fig. 8 Calculations of frequency distributions for energy deposition in a $10 \times 5 \mathrm{~nm}$ cylindrical volume by several high-energy ions. The left ordinate shows the average number of events in the DNA structure in a typical mammalian cell. The right ordinate gives the absolute frequency 


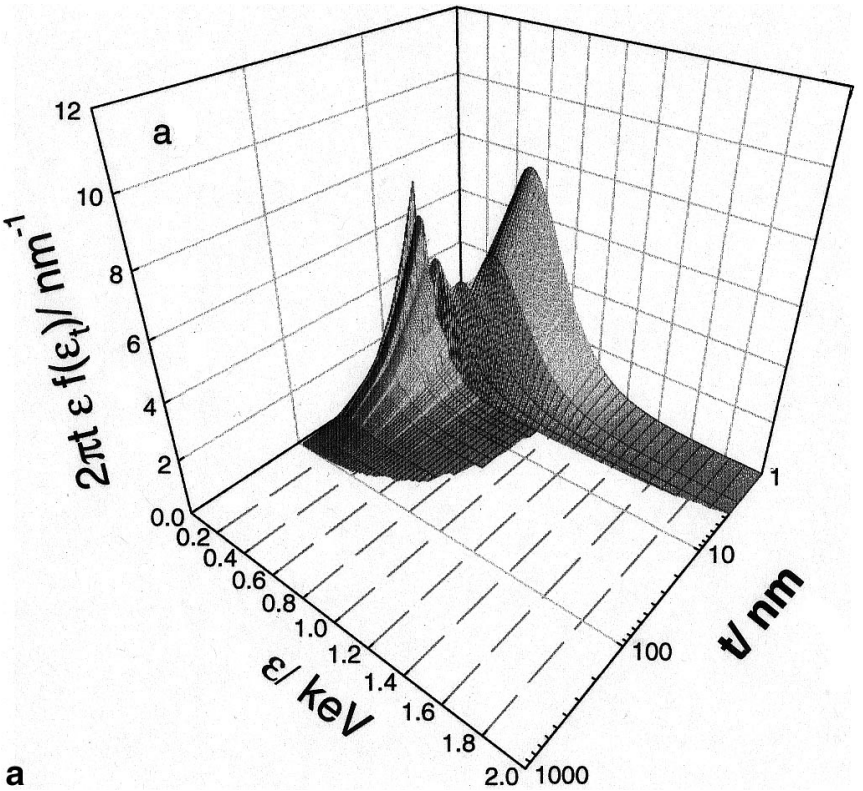

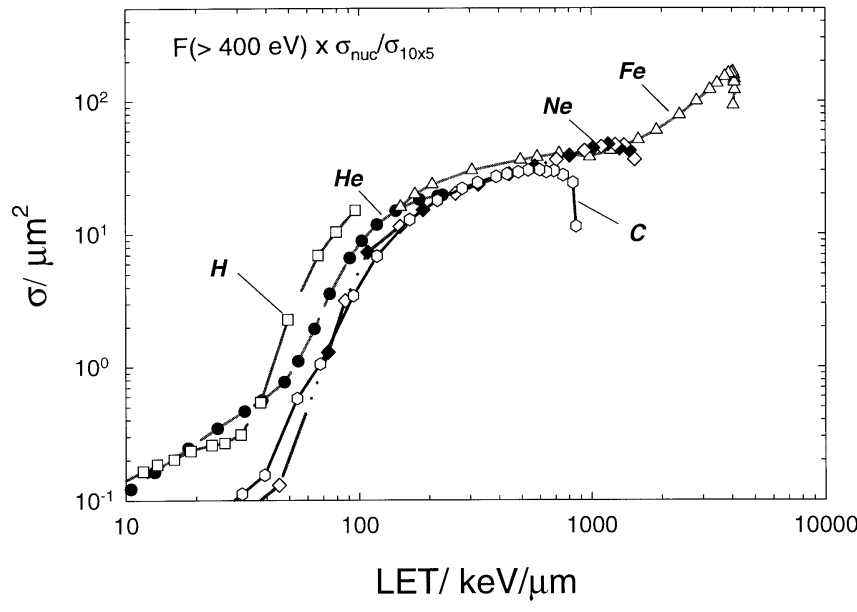

Fig. 10 Calculations of inactivation cross-sections versus LET for several ions. Calculations were made using the frequency distribution for a $10 \times 5 \mathrm{~nm}$ cylindrical target folded with an energy deposition threshold of $400 \mathrm{eV}$ and scaled per particle and by the ratio of the cell nucleus area to the nucleosome area

that low charge and energy (LZE) ions are capable of producing clustered damage at a higher frequency than many HZE ions of interest for space radiation risk studies.

In Fig. 9 we show 3-dimensional mesh plots of the event spectrum multiplied by the differential cross-sectional area, $2 \pi t$, and energy transfer, $\varepsilon$, for $1 \mathrm{MeV} / \mathrm{u}$ alpha-particles and $600 \mathrm{MeV} / \mathrm{u}{ }^{56} \mathrm{Fe}$ ions. For illustrative purposes, we have plotted these with a lower cut-off of $5 \times 10^{-3} \mathrm{~nm}^{-1}$. Due to their large track width, single relativistic HZE ion tracks present the possibility of several genes or even DNA segments in adjacent cells receiving an appreciable number of events. In comparison, highLET alpha-particles are more efficient at transferring large energies to isolated targets such as a nucleosome or chromatin fibre. These results lead to the conclusion that for particles of identical LET, ions of large velocity (i.e. large track width) are less effective than low-energy protons or alpha-particles in damaging isolated DNA segments.

In the review made of the Katz model by Goodhead [4], results of Charlton et al. [77, 78] for frequency distributions from protons and alpha-particles in a $10 \times 5 \mathrm{~nm}$ site representing a nucleosome were shown to behave similarly to the action cross-section model of Katz when an energy threshold of $400 \mathrm{eV}$ for lethal damage was chosen. We extend these calculations to heavy ions here using the frequency-distribution model described above. The action cross-section is found by folding the radial frequency distribution (normalized per particle track) with a probability function for an energy deposition event producing lethal damage. We have scaled this cross-section by the ratio of the nuclear area to the nuclesome area as shown in Fig. 10. Many of the features of the Katz cross-section are reproduced, including the inflection at a saturation value of about $40 \mu \mathrm{m}^{2}$ and

\section{hooks for stopping heavy ions.}

VV for DSB induction $[6,8]$. More comp

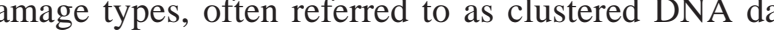
age, involving multiple SSB, DSB, and associated basedamage $[6,8]$ occur mostly for higher energy depositions of $100 \mathrm{eV}$ or more. The comparisons in Fig. 8 show 


\section{Conclusions}

The amorphous track model has used parametric models of electron energy deposition and the primary electron spectrum released by heavy particles to describe the effects of the energy deposition of ions. The resulting spatial distribution of energy deposition can be folded with a physical or biological systems characteristic response to electrons or photons to describe the equivalent effect by ions. Related models to the ion-kill gamma-kill model of Katz are able to include phenomenological descriptions of damage repair, while keeping the underlying description of the amorphous track. Monte Carlo track simulation codes describe features of ion track structure not discussed by amorphous track models, including stochastics and the relative effectiveness of electrons of varying energy. These models can be utilized to describe action cross-sections for cell killing. The comparisons of the radial distribution for electron energies or specific energy may provide new insights into the success of the average track model in describing RBE for diverse radiation fields and approaches to improve this model. In this way, a more modern approach to a phenomenological description of the effects of heavy ions can be developed which builds on the successes of the earlier amorphous track models. For HZE tracks, unique events in tissue may occur due to the large number of cells traversed and the possibility of lateral damage or neighbour cell effects. The amorphous track models offer a unique approach to study such possibilities.

\section{References}

1. Butts JJ, Katz R (1967) Theory of RBE for heavy ion bombardment of dry enzymes and viruses. Radiat Res 30: 855-871

2. Katz R, Ackerson B, Homayoonfar M, Scharma SC (1971) Inactivation of cells by heavy ion bombardment. Radiat Res 47: 402-425

3. Katz R, Zachariah R, Cucinotta FA, Chanxiang Z (1994) Survey of radiosensitivity parameters. Radiat Res 140: 356-365

4. Goodhead DT (1989) Relationship of radiation track structure to biological effect: a re-interpretation of the parameters of the Katz model. Nuclear Tracks Radiat Meas 116: 177-184

5. Goodhead DT (1994) Initial events in the cellular effects of ionizing radiations: clustered damage in DNA. Int J Radiat Biol 65: 7-17

6. Charlton DE, Nikjoo H, Humm JL (1989) Calculation of initial yields of single- and double-strand breaks in nuclei from electrons, protons, and alpha particles. Int J Radiat Biol 56: $1-19$

7. Goodhead DT, Nikjoo H (1989) Track structure analysis of ultrasoft $\mathrm{X}$-rays compared to high and low LET radiations. Int $\mathrm{J}$ Radiat Biol 55: 513-529

8. Nikjoo H, O’Neill P, Goodhead DT, Terrissol M (1997) Computational modeling of low energy electron induced DNA damage by early physical and chemical events. Int J Radiat Biol 71: 467-483

9. Lane DP (1992) p53, Guardian of the genome. Nature 358: $15-16$

10. Polyak K, Xia Y, Zweier JL, Kinzler KW, Vogelstein B (1997) A model for p53-induced apoptosis. Nature 398: 300-305

11. Pines J, Hunter T (1989) Isolation of a human cyclin cDNA: evidence for cyclin mRNA and protein regulation in the cell cycle and for interaction with p34cdc2. Cell 58: 833-846
12. Nurse P (1990) Universal control mechanism regulating onset of M-phase. Nature 344: 503-508

13. Roth DB, Porter TN, Wilson JH (1985) Mechanisms of nonhomologous recombination in mammalian cells. Mol Cell Biol 5: 2599-2607

14. Gellert M, McBlane JF (1995) Steps along the pathway of V(D)J recombination. Philos Trans Biol Sci 347: 43-47

15. Lee JM, Abrahamson JLA, Kandel R, Donehower LA, Bernstein A (1994) Susceptibility to radiation-carcinogenesis and accumulation of chromosomal breakage in p53 deficient mice. Oncogene 9: 3731-3736

16. Scholz M, Kraft G (1994) Calculation of heavy ion inactivation probabilities based on track structure, x-ray sensitivity and target size. Radiat Prot Dosim 52: 29-33

17. Scholz M, Kellerer AM, Kraft-Weyrather W, Kraft G (1997) Computation of cell survival in heavy ion beams for therapy the model and its approximation. Radiat Environ Biophys 36: 59-66

18. Wilson JW, Cucinotta FA, Shinn JL(1993) Cell kinetics and track structure. In: Swenberg CE, et al. (eds) Biological effects and physics of solar and galactic cosmic rays. Plenum Press, New York, pp 295-338

19. Kozubek S, Horneck G, Krasavin EA, Ryznar L (1995) Interpretation of mutation induction by accelerated heavy ions in bacteria. Radiat Res 141: 199-207

20. Kobetich EJ, Katz R (1968) Width of heavy ion tracks in emulsion. Phys Rev 170: 405-411

21. Kobetich EJ, Katz R (1969) Energy deposition by electron beams and $\delta$-rays. Phys Rev 170: 257-265

22. Katz R, Parnell DR (1959) Two proposed experiments for the detection of the Dirac monopole. Phys Rev 116: 236-238

23. ICRU Report 55 (1996) Secondary electron spectra from charged particle interactions. ICRU, Bethesda

24. Bethe HA, Rose ME, Smith LP (1938) The multiple scattering of electrons. Proc Am Philos Soc 78: 573-585

25. LaVerne JA, Mozumder A (1983) Penetration of low-energy electrons in water. Radiat Res 96: 219-234

26. Berger MJ (1972) Energy deposition by low energy electrons: delta-ray effects in track structure, and microdosimetric eventsize spectra. Proc Third Symp on Microdosimetry, Stresa, Italy, Vol. 1, pp 157-177

27. Paretzke HG (1980) Advances in energy deposition theory. In: Thomas RH, Perez-Mendez V (eds) Advances in radiation protection and dosimetry in medicine. Plenum, NY, pp 51-73

28. Cucinotta FA, Katz R, Wilson JW, Dubey RR (1995) Radial dose distributions in the delta-ray theory of track structures. In: Gray TJ, Starace AF (eds) Proceedings of two-center effects in ion-atom collisions. AIP Conference Proceedings, pp 245-265

29. Bizzeti PG, Della Corte M (1959) On the thinning down of tracks of heavy nuclei in nuclear emulsions. Il Nuovo Cimento XI: $317-333$

30. Chatterjee A, Maccabee HD, Tobias CA (1973) Radial cut-off LET and radial cut-off dose calculations for heavy charged particles in water. Radiat Res 54: 479-494

31. Fain J, Monnin M, Montret M (1977) Spatial energy distribution around heavy ion paths. Radiat Res 57: 379-389

32. Kiefer J, Straaten H (1986) A model of ion track structure based on classical collision dynamics. Phys Med Biol 31: 1201-1209

33. Zhang CX, Liu XW, Li MF, Luo DL (1994) Numerical calculation of the radial distribution of dose around the path of a heavy ion. Radiat Prot Dosim 52: 93-96

34. Waligorski MPR, Hamm RN, Katz R (1986) Radial distribution of dose about the path of a heavy ion in liquid water. Nucl Tracks Radiat Meas 11: 309-319

35. Brandt W, Ritchie RH (1974) Primary processes in the physical stage. In: Gray TJ, Starace AF (eds) Physical mechanisms in radiation biology. Tech. Info. Center, US Atomic Energy Commission, pp 20-29

36. Wilson JW, Townsend LW, Schimmerling W, Nealey JE, Khandelwal GS, Khan F, Cucinotta, FA, Simonsen LS, Shinn JL, Norbury JW(1991) Transport methods and interactions for space radiation. (NASA RP 1257) NASA, Washington DC 
37. Holley WR, Chatterjee A (1996) Clusters of DNA damage induced by ionizing radiation: formation of short DNA fragments. I. Theoretical modeling. Radiat Res 145: 188-199

38. Kraft G, Krämer M (1993) LET and track structure. In: Lett J, Sinclair WK (eds) Advances in radiation biology. Academic Press, San Diego, pp 1-50

39. Wingate CL, Baum JW (1976) Measured radial distributions of dose and LET for alpha and proton beams in hydrogen and tissue-equivalent gas. Radiat Res 65: 1-19

40. Varma MN, Baum JW (1980) Energy deposition in nanometer regions by $377 \mathrm{MeV} /$ nucleon ${ }^{20} \mathrm{Ne}$ ions. Radiat Res 81: 355-363

41. Katz R, Wesley S (1991) Cross sections for single and double strand breaks in SV-40 virus in E0 buffer after heavy ion irradiation: experiment and theory. Radiat Environ Biophys 30: $81-85$

42. Cucinotta FA, Nikjoo H, Wilson JW, Katz R, Goodhead DT (1997) Radial dose model of SSB, DSB, deletions, and comparisons to Monte Carlo track structure simulations. In: Goodhead DT, O’Neill P, Menzel HG (eds) Microdosimetry and interdisciplinary approach. Royal Society of Chemistry, Cambridge, pp 35-38

43. Belli M, Cera F, Cherubini R, Haque AMI, Ianzini F, Moschini G, Sapora O, Simone G, Tabocchini MA, Tiveron P (1993) Inactivation and mutation induction in V79 cells by low energy protons: re-evaluation of the results at the LNL facility. Int J Radiat Biol 63: 331-337

44. Thacker J, Stretch A, Stevens MA (1979) Mutation and inactivation of cultured mammalian cells exposed to beams of accelerated heavy ions. II. Chinese hamster V79 cells. Int J Radiat Biol 36: 137-148

45. Kiefer J, Schneider E (1994) Mutation induction by heavy ions. Adv Space Res 14: 257-265

46. Stoll U, Schmidt A, Schneider E, Kiefer J (1995) Killing and mutation of Chinese hamster V79 cells exposed to accelerated oxygen and neon ions. Radiat Res 142: 288-294

47. Madhvanath U, Raju MR, Kelly LS (1976) Survival of human lymphocytes after exposure to densely ionizing radiations. In: Ballou J (ed) Radiation and the lymphatic system. Tech Info Center, Springfield, pp 125-139

48. Lett JT, Cox AE, Story MD (1989) The role of repair in the survival of mammalian cells from heavy ion irradiation: approximation to the ideal case of target theory. Adv Space Res 9: 99-104

49. Weissbod U, Buckeer H, Horneck G, Kraft G (1992) Heavyion effects on bacteria spores: the impact parameter dependence of the inactivation. Radiat Res 129: 250-257

50. Cucinotta FA, Wilson JW, Katz R, Atwell WJ, Badhwar GD, Shavers MR (1996) Track structure and radiation transport model for space radiobiology studies. Adv Space Res 18: $183-133$

51. Cucinotta FA, Wilson JW, Shavers MR, Katz R (1996) Effects of track structure and cell inactivation on the calculation of heavy ion mutation rates in mammalian cells. Int J Radiat Biol 69: 593-600

52. Goodhead DT, Munson RJ, Thacker J, Cox R (1980) Mutation and inactivation of cultured mammalian cells exposed to beams of accelerated heavy ions. IV. Biophysical interpretation. Int J Radiat Biol 37: 135-167

53. Chernbonnel-Lasserre C, Gauny S, Kroneberg A (1996) Suppression of apoptosis by Bcl-2 or Bcl-XL promotes susceptibility to mutagenesis. Oncogene 13: 1489-1497

54. Sasaki H, Yatagi F, Kanai T, Furusawa Y, Hanaoka F, Zhu W, Mehnati P (1997) Dependence of induction of interphase cell death of Chinese hamster ovary cells exposed to accelerated heavy ions on linear energy transfer. Radiat Res 148: 449-454

55. Kozubek S, Horneck G, Krasavin EA, Ryznar L (1995) Interpretation of mutation induction by accelerated heavy ions in bacteria. Radiat Res 141: 199-207

56. Cucinotta FA, Wilson JW (1994) Initiation-promotion model for tumor prevalence from high energy and charge radiation. Phys Med Biol 39: 1811-1831
57. Cucinotta FA, Wilson JW (1995) Initiation-promotion model of tumor prevalence in mice from space radiation exposures. Radiat Environ Biophys 34: 145-149

58. Katz R, Scharma SC (1975) RBE-dose relations for neutrons and pions. Phys Med Biol 20: 410-419

59. Curtis SB (1989) The Katz cell-survival model and beams of heavy charged particles. Nucl Tracks Radiat Meas 16: 97-103

60. Curtis SB (1977) Calculated LET distributions of heavy ion beams. Int J Radiat Oncol Biol Phys 3: 87-91

61. Wilson JW, Shavers MR, Badavi FF, Miller J, Shinn JL, Costen RC (1994) Nonpertubative methods in HZE propagation. Radiat Res: 241-248

62. Grahn D (ed) (1971) HZE particle effects in manned space flight. National Academy of Sciences. Washington DC

63. Todd P, Schroy CB, Schimmerling W, Vosburgh KG (1973) Cellular effects of heavy charged particles. In: Sneath PHA (ed) Proceedings of the Open Meeting of the Working Group on Space Biology of the Fifteenth Plenary Meeting of COSPAR. Akademie-Verlag, Berlin, pp 261-270

64. Todd P (1989) Stochastics of HZE-induced microlesions. Adv Space Res 9(10): 31-34

65. Sakhi S, Bruce A, Sun N, Tocco G, Baudry M, Schreiber SS (1994) p53 induction is associated with neuronal damage in the central nervous system. Proc Natl Acad Sci 91: 7525-7529

66. Lett JT, Williams GR (1993) Effects of LET on the formation and fate of radiation damage to photoreceptor cell component of the rabbit retina: implications for the projected manned mission to Mars. In: Swenberg CE, Horneck G, Stassinopoulos EG (eds) Biological effects of solar and galactic cosmic radiation, part A. Plenum Press, NY, pp 185-201

67. Katz R, Hoffman W (1982) Biological effects of low dose of ionizing radiations: particle tracks in radiobiology. Nucl Instrum Methods 203: 433-442

68. Cucinotta FA, Katz R, Wilson JW, Townsend LW, Shinn JL, Hajnal F (1991) Biological effectiveness of high-energy protons: target fragmentation. Radiat Res 127: 130-137

69. Cucinotta FA, Dubey RR (1994) Alpha cluster description of excitation energies in ${ }^{12} \mathrm{C}\left({ }^{12} \mathrm{C}, 3 \alpha\right) \mathrm{X}$ at $2.1 \mathrm{GeV}$. Phys Rev C 50: 979-984

70. Kadhim M, MacDonald DA, Goodhead DT, Lorimore SA, Marsden SJ, Wright EG (1992) Transmission of chromosomal instability after plutonium $\alpha$-particle irradiation. Nature 355: $738-740$

71. Morgan WF, Day JP, Kaplan MI, McGhee EM, Limoli CL (1996) Genomic instability induced by ionizing radiation. Radiat Res 146: 247-258

72. Lorimore SA, Kadhim MA, Pocock DA, Papworth D, Stevens DL, Goodhead DT, Wright E (1998) Chromosomal instability in the descendants of unirradiated surviving cells after $\alpha$-particle irradiation. Proc Natl Acad Sci 95: 5730-5733

73. Cucinotta FA, Nikjoo H, Goodhead DT (1998) The effects of delta-rays on the number of particle-track traversals per cell in laboratory and space exposures. Radiat Res 150: 115-119

74. Cucinotta FA, Katz R, Wilson JW (1998) Radial distribution of electron spectrum from high energy ions. Radiat Environ Biophys 37: 259-265

75. Nikjoo H, Goodhead DT, Charlton DE, Paretzke HG (1991) Energy deposition in small cylindrical targets by mono-energetic electrons. Int J Radiat Biol 60: 739-756

76. Goodhead DT, Nikjoo H (1990) Current status of ultrasoft xrays and track structure analysis as tools for testing and developing biophysical models of radiation action. Radiat Prot Dosim 31: 343-350

77. Charlton DE, Goodhead DT, Wilson WE, Paretzke HG (1985) The deposition of energy in small cylindrical targets by high LET radiations. Radiat Prot Dosim 13: 123-125

78. Charlton DE, Goodhead DT, Wilson WE, Paretzke HG (1985) Energy deposition in cylindrical volumes: (a) protons, energy $=0.3 \mathrm{MeV}$ to $4.0 \mathrm{MeV}$, (b) alpha particles, energy $=1.2 \mathrm{MeV}$ to $20.0 \mathrm{MeV}$. (MRC Radiobiology Unit Monograph 85/1) MRC, Chilton, UK 